\title{
Identification and management of unsafe behaviors of lifting workers on the construction site based on HAZOP
}

\author{
Yunong Niu, Quan Chen \\ Tianjin University of Technology, 300384 Tianjin, China
}

\begin{abstract}
Hazard and operability study (HAZOP), which is applied to identify the hazards of a system and its operability, finds application in identifying unsafe behaviors of operators after redefining the "guide words" and "process requirements". In this paper, unsafe behaviors of lifting workers on the construction site and the risk they brought were identified using the redefined HAZOP. Then, the causes of these behaviors were revealed after sorting and analysing these behaviors.. Finally, based on these causes, appropriate management measures were developed for effectively reducing accidents in lifting operations.
\end{abstract}

\section{Introduction}

In modern building construction, lifting operations have played an increasingly important role. As the operation requires the skilled cooperation of people, operators involved should cooperate with each other with mutual attention, which, however, is of great difficulty. Therefore, accidents caused by lifting operations occur frequently, accounting for over $7 \%$ of accidents at the construction site ${ }^{[1]}$. As one of the most fundamental theories of safety engineering, the cause-effect chain, whether modern or classic, holds that the direct causes of an accident are unsafe behaviors of personnel and the unsafe state of things, of which unsafe behaviors of personnel are believed to be the main reason in light of accident-causing theory. According to Heinrich's estimation, more than $80 \%$ of the accidents are due to unsafe behaviors of personnel ${ }^{[2]}$. Hazard and operability study (HAZOP) is applicable not only to identifying the impact of parameter changes on the system during an operation process, but also to judging unsafe behaviors of personnel in operations. In this paper, based on the lifting operation at a construction site, HAZOP was conducted on the lifting operation of the wheel crane to identify unsafe behaviors of personnel in the lifting process, as well as their causes and consequences; in addition, targeted management measures were proposed based on the analyses.

\section{HAZOP}

HAZOP is carried out by an experienced multi-disciplinary team on hazards and operability problems of an operation process. These problems are actually a series of "deviations", that is, the process conditions deviate from the design intent [3]. At present, HAZOP is mainly used for operating risk analysis both at home and abroad [4] and a large number of accidents are resulted from deviations in personnel operations. Hence, a systematic and comprehensive review of operating procedures can also effectively identify unsafe behaviors in personnel operations by adopting HAZOP.

\subsection{Feasibility of HAZOP applied to the identification of unsafe behaviors of personnel}

The Safety Operation Instructions (hereinafter referred to Instructions) is designed for safe production, and operators should comply with it in operations ${ }^{[5]}$. The on-site personnel can minimize accidents by following the Instructions, and they may fail if their behaviors deviate from the requirements in the Instructions, which is called "unsafe behaviors of personnel". Therefore, the procedural and behavioral requirements in the Instructions can be regarded as "process requirements", and unsafe behaviors of personnel are defined as "deviations". Under this circumstance, analysis is conducted on each node in the process based on the Instructions to identify the "deviations" of personnel's behaviors by utilizing "guide words", so as to identify unsafe behaviors of lifting workers on the accident site.

\subsection{Guide word}

Guide words, which are simple words for qualitative or quantitative design of parameters, guide the identification of hazards in the operation ${ }^{[6]}$. The HAZOP team analyzes each node divided according to the Instructions by using predetermined "guide words" to identify through inquiry deviations from design intent that lead to unfavorable consequences. With "guide words", analysts can concentrate on the analysis with imaginative thinking, thus proposing and discussing ideas for complete and comprehensive analysis. The following "guide words" 
are needed for HAZOP, as given in Table 2-1.

Table 2-1. Guide words of operation procedures.

\begin{tabular}{|c|c|}
\hline Guide Word & Meaning \\
\hline NOT DONE & Omission error \\
\hline MORE OR LESS THAN & Commission error. E.g. the valve opens improperly. \\
\hline PART OF & Commission error. Behaviors deviate from the goal. \\
\hline OTHER THAN & $\begin{array}{l}\text { Mistake error or intentional violation. E.g. completing a completely different task by } \\
\text { following a strong, previously-formed habit. }\end{array}$ \\
\hline $\begin{array}{l}\text { EARLY } \\
\text { LATE } \\
\text { BEFORE } \\
\text { AFTER }\end{array}$ & $\begin{array}{l}\text { Commission error - Miss sequence. Compared to the required order, the task completed is: } \\
\text { early (earlier than the given time), late (later than the given time), before (ahead of the given } \\
\text { sequence), and after (behind the given sequence). }\end{array}$ \\
\hline
\end{tabular}

3 Identification and management of unsafe behaviors of lifting workers on the construction site

\subsection{Identification of unsafe behaviors in lifting operations}

Lifting operations on the construction site involve crane drivers and lifting workers, so both Crane Safety
Operation Regulations and Safety Operation of Construction Workers should be considered in the analysis. Before the analysis, the following concepts must be clarified:

(1) Deviation: deviation = guide words + operation behaviors. In this analysis, the deviation refers to unsafe behaviors of personnel.

(2) Risk: The risk here refers to accidents that may occur during lifting operations.

Table 3-1. HAZOP analysis results of lifting operations on the construction site

\begin{tabular}{|c|c|c|c|c|c|}
\hline $\begin{array}{l}\text { Producti } \\
\text { on } \\
\text { activity: }\end{array}$ & \multicolumn{3}{|c|}{ Lifting operations on the construction site } & Documentation: & \\
\hline $\begin{array}{l}\text { Operatio } \\
\mathrm{n} \\
\text { process/ } \\
\text { instructio } \\
\text { ns }\end{array}$ & \multicolumn{3}{|c|}{$\begin{array}{c}\text { Crane Safety Operation Regulations \& Safety Operation of } \\
\text { Construction Workers }\end{array}$} & Date of Meeting: & \\
\hline No. & Procedures & Behaviors & Guide Words & Deviations & Risks \\
\hline 1 & \multirow{3}{*}{$\begin{array}{l}\text { Operators' } \\
\text { equipment } \\
\text { preparation }\end{array}$} & $\begin{array}{l}\text { Correctly wear full labor } \\
\text { insurance supplies }\end{array}$ & LESS & $\begin{array}{l}1 \text { Wear inadequate labor } \\
\text { insurance supplies; } \\
2 \text { Incorrectly wear labor } \\
\text { insurance supplies, e.g. } \\
\text { awry safety helmet }\end{array}$ & Lifting injuries \\
\hline \multirow[b]{2}{*}{2} & & $\begin{array}{l}\text { The director wear the } \\
\text { directing sleeve correctly }\end{array}$ & NOT DONE & $\begin{array}{l}1 \text { Not wear the directing } \\
\text { sleeve }\end{array}$ & \multirow{2}{*}{ Lifting injuries } \\
\hline & & $\begin{array}{l}\text { (a red and white sleeve on } \\
\text { the middle of the left } \\
\text { upper arm) }\end{array}$ & PART OF & $\begin{array}{l}1 \text { Wear the directing sleeve } \\
\text { on the right arm; } \\
2 \text { Wear the directing sleeve } \\
\text { on the lower arm }\end{array}$ & \\
\hline 3 & $\begin{array}{l}\text { Vehicles } \\
\text { preparation }\end{array}$ & $\begin{array}{l}\text { Check the crane with } \\
\text { inspection standards listed }\end{array}$ & NOT DONE & Not check vehicles & $\begin{array}{c}\text { Lifting and } \\
\text { vehicle injuries }\end{array}$ \\
\hline
\end{tabular}




\begin{tabular}{|c|c|c|c|c|c|}
\hline & & $\begin{array}{l}\text { in Cranes Inspection } \\
\text { Items and Technical } \\
\text { Standards }\end{array}$ & LESS & $\begin{array}{l}\text { Not check vehicles with } \\
\text { required inspection } \\
\text { standards } \\
\end{array}$ & \\
\hline & & & $\begin{array}{l}\text { OTHER } \\
\text { THAN }\end{array}$ & $\begin{array}{l}\text { Multi-operators think others } \\
\text { have finished checking }\end{array}$ & \\
\hline \multirow[t]{2}{*}{4} & & $\begin{array}{l}\text { Check water volume in } \\
\text { the tank and add water as } \\
\text { required (It is a must }\end{array}$ & NOT DONE & $\begin{array}{l}1 \text { Not check water volume } \\
\text { in the tank } \\
2 \text { Not add cooling water }\end{array}$ & \multirow{2}{*}{$\begin{array}{l}1 \text { Damage to } \\
\text { engine } \\
2 \text { Scald }\end{array}$} \\
\hline & & When no water is visioie.) & LESS & Add insufficient water & \\
\hline \multirow[t]{2}{*}{5} & & Add diesel & NOT DONE & Not add diesel & \multirow{2}{*}{$\begin{array}{l}\text { Small risk yet } \\
\text { delaying work } \\
\text { progress }\end{array}$} \\
\hline & & & LESS & Not fill the diesel tank & \\
\hline \multirow{3}{*}{6} & \multirow{3}{*}{$\begin{array}{l}\text { Crane } \\
\text { driving to } \\
\text { the site }\end{array}$} & $\begin{array}{l}\text { Lift the hook to the alarm } \\
\text { position }\end{array}$ & LESS & $\begin{array}{l}\text { Not lift the hook to the } \\
\text { alarm position }\end{array}$ & $\begin{array}{l}\text { Small risk yet } \\
\text { reducing the } \\
\text { service life of the } \\
\text { hook }\end{array}$ \\
\hline & & \multirow{2}{*}{$\begin{array}{l}\text { Lower the arm (The angle } \\
\text { between the arm and } \\
\text { ground ranges from } 30^{\circ} \text { to } \\
\left.45^{\circ}\right)\end{array}$} & LESS & $\begin{array}{l}\text { The angle between the arm } \\
\text { and ground is less than } 30^{\circ} \text {. }\end{array}$ & Vehicle injuries \\
\hline & & & MORE & $\begin{array}{l}\text { The angle between the arm } \\
\text { and ground is more than } \\
45^{\circ} \text {. }\end{array}$ & Vehicle injuries \\
\hline
\end{tabular}

\subsection{Analysis of factors leading to deviation}

The identified unsafe behaviors of personnel can be divided into two categories after they are sorted and analyzed, according to whether behavioral subjects are aware of the hazard of their behaviors before they act ${ }^{[7]}$ :

(1) If the subject does not recognize the hazard before the action, it is called unintentional violation, including commission errors and mistake errors;

(2) If the subject is aware of the hazard before taking action, it is called intentional violation;

The main causes of unintentional violations include the on-site personnel's abilities, physiology, psychology, auditory, visual and tactile sensations, judgment, and environmental conditions that affect personnel's behaviors on site, while those of intentional violations cover consciousness, psychology, and thinking.

\section{Management of unsafe behaviors in lifting operation}

The unsafe behaviors of personnel are a direct factor and the most important reason for accidents. Based on the results of HAZOP identification and unsafe behavior analysis, the following measures for controlling unsafe behaviors are proposed:

\subsection{Safe management}

Formulate safety operation regulations targeting the features of enterprises, positions, and types of work. Carry out regular safety education and technical training in addition to rational division of labor to enhance personnel's safety awareness and reduce errors.
(1) Conduct three-level safety education and technical training for new workers;

(2) Make specific training plans for special type of work;

(3) Formulate safety operation regulations and implementation measures for each position and type of work;

(4) Raise safety awareness by safety education through accident lessons, bulletin boards, televisions and exhibitions;

(5) Launch hazard prediction activities to improve operators' ability to identify hazards;

(6) Arrange work rationally and give play to the expertise of operators;

(7) Relieve personnel's fatigue by measures such as coffee creak and health care, and protection against hot, cold and freezing conditions;

(8) Forbid overtime working according to regulations, continuous overwork or working with an illness;

\subsection{Safe operation}

(1) Adopt administrative and economic measures to promote safe and standard operations of various types of work and reduce personnel's unsafe behaviors;

(2) Combine ideological and administrative measures to conduct all-round, multi-level, and joint security management by the Party, government, the labor union, the League Committee, and security departments;

(3) Establish supervision positions for operational standards, and encourage workers to perform standard operations and supervise each other; 


\subsection{Safe environment}

(1) Conduct civilized production and ensure the safe passage unblocked which meets regulations;

(2) Store tools and spares rationally;

(3) Require operators using and wearing labor insurance supplies reasonably and neatly;

(4) Improve the microclimate conditions of the workplace, including temperature, humidity and lighting to agree with personnel's psychological and physiological conditions;

(5) Apply eye-catching, vivid and different geometric shapes and colors to the operating area of device;

\subsection{Improvement of the supervision and inspection system}

Changes in behaviors can never be accomplished overnight. Therefore, the elimination of unsafe behaviors in operations relies on not only education and training but also effective supervision and inspection. In addition to the aforementioned measures, Unsafe Behaviors Inspection Standards for on-site personnel should be formulated based on the results of HAZOP identification. Then, the unsafe behaviors inspection system should be set up according to the organizational structure of the enterprise.

\section{Conclusion}

(1) Effective identification can be conducted on unsafe behaviors of personnel during lifting operations and the accidents they may cause through the systematic analysis of the lifting operation on the accident site by employing HAZOP.

(2) After analyzing the causes of identified personnel's unsafe behaviors, appropriate management measures can be formulated to effectively reduce both personnel's unsafe behaviors in the lifting operation at the construction site and the occurrence of lifting accidents.

\section{Reference}

1. H. Lin. Study on the Relationship between Cognitive Bids and Unsafe Behavior of Construction Workers [D]. Tianjin: Tianjin University of Technology, 2016.

2. E. Heinrich, D. Peterson, N. Roos. Industrial Accident Prevention (McGraw-Hill Book Company, New York, 1980)

3. Z. Bin, Z. Dong-Feng, Z. Le-ping, et al. CSSJ 17, 160-164 (2007)

4. X. Wang, H. Tao, SHE 2, 6-9 (2005).

5. T. Kletz. What Went Wrong?: Case histories of

6. process plant disasters-4thed (Gulf Publishing Company, Houston, 1998)

7. Z. Yue, S. Chao, F. Lai-hua. CSSJ 7, 147-150 (2011) .

8. Y. Gui, D. Hong-liang, W. Hong-xia. OJSST 11, 171-176 (2015). 